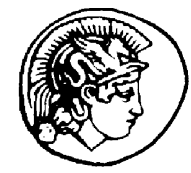

PERGAMON

International Journal of Impact Engineering 24 (2000) 277-298

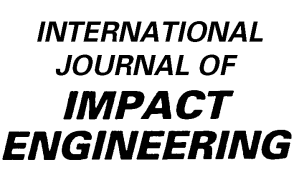

www.elsevier.com/locate/ijimpeng

\title{
High strain rate compressive behaviour of aluminium alloy foams
}

\author{
V.S. Deshpande, N.A. Fleck* \\ Cambridge University Engineering Department, Trumpington Street, Cambridge, CB2 1PZ, UK
}

Received 30 September 1998; received in revised form 17 September 1999

\begin{abstract}
The high strain rate compressive behaviour of two cellular aluminium alloys (Alulight and Duocel) has been investigated using the split Hopkinson pressure bar and direct impact tests. It is found that the dynamic behaviour of these foams is very similar to their quasi-static behaviour. The plateau stress is almost insensitive to strain rate, for strain rates $\dot{\varepsilon}$ up to $5000 \mathrm{~s}^{-1}$. Deformation is localised in weak bands in the Alulight foam but is spatially uniform for the Duocel foam, over the full range of strain rates $10^{-3} \mathrm{~s}^{-1} \leqslant \dot{\varepsilon} \leqslant 5000 \mathrm{~s}^{-1}$. (C) 2000 Elsevier Science Ltd. All rights reserved.
\end{abstract}

Keywords: Metallic foams; Quasi-static and dynamic crushing; Split Hopkinson pressure bar

\section{Introduction and materials chosen for study}

Foamed aluminium alloys are ultra-light solids which absorb considerable energy by plastic dissipation in compression. Their cellular microstructure endows them with the ability to undergo large deformation at nearly constant nominal stress (plateau stress). It is expected that they will find application in absorbing impacts and shocks (for example in crash barriers and in blast mitigators). Such use of aluminium foams requires a knowledge of the effect of impact velocity and strain rate on their compressive behaviour. Previous studies on the dynamic properties of cellular materials have been mainly conducted on materials with periodic morphologies (for example, arrays of tubes [1] and honeycombs [2-5]). These studies found an increase of between 20 and $70 \%$ in the dynamic crush strength at impact velocities of the order of $30 \mathrm{~m} \mathrm{~s}^{-1}$ compared with the corresponding quasi-static value. In contrast, Kenny [6] reported that the specific energy absorption of

* Corresponding author. Tel.: + 44-01223-332650; fax: + 44-01223-332662.

E-mail address: nafl@eng.cam.ac.uk (N.A. Fleck) 
Alcan foam (an aluminium alloy foam) was independent of applied strain rate in the range $10^{-3}-10^{3} \mathrm{~s}^{-1}$ (the impact velocity at a strain rate of $10^{3} \mathrm{~s}^{-1}$ was $10 \mathrm{~m} \mathrm{~s}^{-1}$ ). No measurements were made however, of the stress-strain curve under dynamic and quasi-static loadings. In line with the findings of Kenny, Lankford and Dannemann [7] found that the compressive strength of Doucel aluminium foam was insensitive to the applied strain rate in the range $10^{-3}-1200 \mathrm{~s}^{-1}$. Thus, there is growing evidence that the strength of foamed metals is insensitive to applied strain rate in the range $10^{-3}-10^{3} \mathrm{~s}^{-1}$.

In this paper the high strain rate compressive behaviour of Alulight and Duocel is investigated using the split Hopkinson pressure bar and direct impact tests. Impact velocities of up to $50 \mathrm{~m} \mathrm{~s}^{-1}$ and strain rates of up to $5000 \mathrm{~s}^{-1}$ are employed; these are within the practical range for many applications of these materials. Alulight is a closed cell foam, manufactured by the Department of Powder Metallurgy, Slovak Academy of Sciences. ${ }^{1}$ The composition of the cell wall material is $\mathrm{Al}-\mathrm{Mg} 0.6-\mathrm{Si0} .3$, the relative density varies between 0.16 and 0.40 and the average cell size is approximately $1 \mathrm{~mm}$. The open-cell Duocel foam comprises an Al6101-T6 alloy with a relative density of 0.070 and an average cell size of $1.2 \mathrm{~mm}$. Further details on the structure, manufacturing processes and names of suppliers of these foams are given by Ashby et al. [8]. A significant factor in choosing these two foams is their small cell size: this allows for the use of relatively small specimens for representative tests.

\section{Background}

Studies on the dynamic properties of cellular materials (e.g. wood, honeycombs, etc.) have attributed the strength increase under dynamic loading conditions to micro-inertial effects and to shock wave propagation. These phenomena are discussed here in the light of their relevance to the dynamic response of aluminium alloy foams.

\subsection{Micro-inertial effects}

The micro-inertia of the individual cell walls can affect the deformation of cellular structures as discussed by Klintworth [9] and more recently by Reid and co-workers [10-13]. Under dynamic loading the collapse mode may switch from the quasi-static mode to a new mode involving additional stretching which dissipates more energy. Thus, an observed rate-sensitive response can have an inertial origin. Calladine and English [14] examined this phenomenon for two classes of structures, Type I and II, as sketched in Fig. 1. Type I structures have a "flat topped" quasi-static stress versus strain curve: under dynamic loading micro-inertia plays little role and the quasi-static bending mode of collapse is maintained. In contrast, Type II structures display a strongly softening bending mode of collapse under quasi-static conditions. However, when struck at a high velocity, lateral inertia forces induce an initial phase of axial compression of the struts. Consequently, the stresses and plastic work are enhanced before the bending mechanism is recovered. Tam and

\footnotetext{
${ }^{1}$ Contact address: Dr. F. Simancik, Department of Powder Metallurgy, Slovak Academy of Sciences, Racianska 75, P.O. Box 15, 8308 Bratislava, Slovakia.
} 


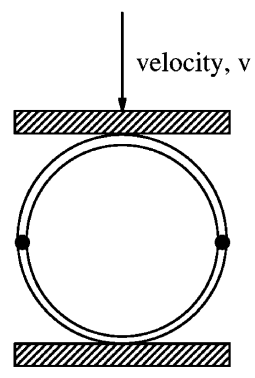

Type I

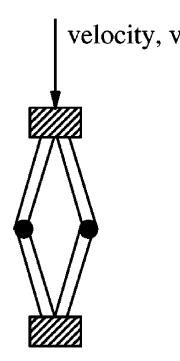

Type II

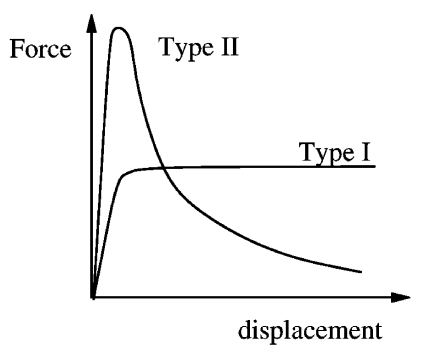

(b) Quasi-static force-displacement curves for each type of structure

Fig. 1. Types of velocity-sensitive structures.

Calladine [15] showed that the elevation in plastic work is sensitive to the initial misalignment of the structure: a misalignment exceeding a few degrees eliminates the micro-inertia effect.

It appears from recent impact investigations of Zhao and Gary [5] that aluminium honeycombs compressed in the out-of-plane direction (normal to the hexagonal cells) behave as Type II structures, whereas the in-plane response is that of a Type I structure. The out-of-plane static response displays a peak load and subsequent softening behaviour, characteristic of a Type II structure. Under dynamic loading, the out-of-plane strength increases by $40 \%$ when the impact velocity is increased from about $5 \times 10^{-4}-30 \mathrm{~m} \mathrm{~s}^{-1}$. In contrast, the in-plane static response is stable and displays negligible elevation in crush strengths for velocities of up to $30 \mathrm{~m} \mathrm{~s}^{-1}$.

Reid and co-workers [10-13] have investigated the effect of impact velocity on the axial and transverse crushing strengths of woods. They found that wood loaded along the grain has a softening quasi-static response suggestive of a Type II structure. For velocities in the range of 30-300 $\mathrm{m} \mathrm{s}^{-1}$ the dynamic crushing strength along the grain is about 2.3 times the static strength, see for example Reid and Peng [13]. They argue that this elevation is due to micro-inertia in the manner observed for a Type II structure. On the other hand, Reid and Peng [13] found a negligible increase in the dynamic transverse strength of woods due to micro-inertia effects. This is consistent with the observation that the transverse compressive response is that of a Type I structure under quasi-static loading.

We note that metallic foams behave as Type I structures, with "flat topped" quasi-static stress versus strain curves [16-18]. Current commercial foams contain many imperfections and deform predominantly by the bending of cell edges (see $[19,20]$ ). It is thus expected that micro-inertial effects play little role in enhancing the dynamic crush strengths of metallic foams.

\subsection{Shock wave propagation}

When a foam is impacted at high velocity, a shock wave propagates through the foam. In order to estimate the elevation in collapse stress with impact velocity we shall consider a simple, one-dimensional shock model, as described by Reid and Peng [13] for the behaviour of wood. 


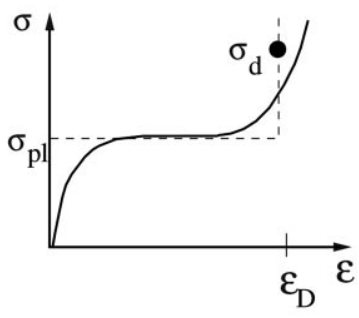

(a) Idealised stress-strain curve

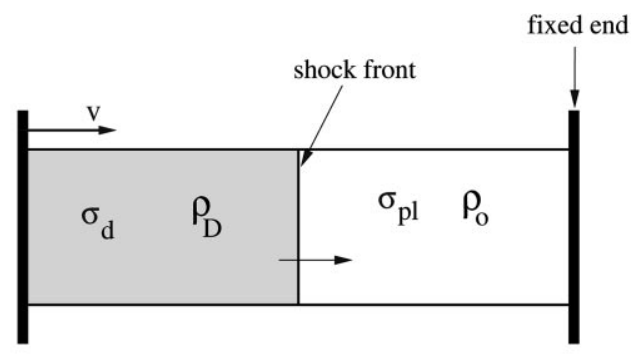

(b) shock model parameters

Fig. 2. Plastic shock wave propagation through a foam.

Harrigan et al. [4] have already used this model to analyse the dynamic crushing of aluminium honeycombs. It is based upon the assumption that the uniaxial stress versus strain response of the material is that of a rigid-perfectly-plastic locking solid as shown in Fig. 2a. This embodies two important features of the inelastic behaviour of foams, namely the plateau stress $\sigma_{\mathrm{pl}}$ and a densification or lock-up strain $\varepsilon_{\mathrm{D}}$.

Consider the impact of one end of a stationary bar by a massive striker at a velocity $v$, as defined in Fig. 2b. The bar is homogeneous and made from a material of idealised constitutive law as shown in Fig. 2a. After impact a shock wave moves from the impacted end to the opposite fixed end of the bar. Assuming rigid-plastic behaviour, the stress ahead of the shock wave equals $\sigma_{\mathrm{pl}}$. The material behind the shock front has attained a strain $\varepsilon_{\mathrm{D}}$, its particle velocity is $v$, its density has been raised from the initial value $\rho_{0}$ to the densification value $\rho_{\mathrm{D}}$, and the compressive stress has been raised to $\sigma_{\mathrm{d}}$. Following Reid and Peng [13], the enhanced dynamic plateau stress $\sigma_{\mathrm{d}}$ is given by

$$
\sigma_{\mathrm{d}}=\sigma_{\mathrm{p} 1}+\frac{\rho_{0} v^{2}}{\varepsilon_{\mathrm{D}}}
$$

Now, for a typical aluminium alloy foam, we can assume $\rho_{0}=900 \mathrm{~kg} \mathrm{~m}^{-3}, \varepsilon_{\mathrm{D}}=0.8$ and $\sigma_{\mathrm{pl}}=15 \mathrm{MPa}$. We conclude that shock propagation effects become important (i.e. the static strength is enhanced by more than 20\%) at impact velocities exceeding about $50 \mathrm{~m} \mathrm{~s}^{-1}\left(180 \mathrm{~km} \mathrm{~h}^{-1}\right)$. These velocities are greater than those encountered in many practical applications of metallic foams. At velocities above the critical velocity, $v_{\text {crit }} \approx 50 \mathrm{~m} \mathrm{~s}^{-1}$, shock wave effects are expected to become important and the response becomes dependent upon impact velocity.

Here, we adopt the criterion of a $20 \%$ elevation in strength to define the impact velocity at which shock waves become important. This is consistent with the fact that metallic foams are highly heterogeneous imperfect materials with a dispersion strength of the order of $20 \%$. Quasi-static tests show that macroscopic straining occurs by the collapse of spatially random and uncorrelated bands (see for example [16,17]). Thus, it is not expected that a shock wave will propagate along the length of the specimen until the dynamic stress enhancement exceeds the scatter in strength. 


\section{Description of experimental techniques}

Compression tests were performed on the Alulight foam (of relative density $0.17-0.4$ ) and on the Duocel foam (of relative density 0.070), at strain rates in the range $10^{-3}-5000 \mathrm{~s}^{-1}$. Tests at the strain rates in the range $10^{-3}-100 \mathrm{~s}^{-1}$ were performed using a servo-hydraulic test machine, while tests at strain rates in the range $1000-5000 \mathrm{~s}^{-1}$ were performed using a split Hopkinson bar and a direct impact arrangement, as detailed below.

The specimens were circular cylinders of diameter $10 \mathrm{~mm}$ and length $10 \mathrm{~mm}$; with this choice of specimen dimensions, the specimens have 6-8 cells in all directions. The specimens were cut to shape by spark machining to minimise damage to the cell edges. For the tests performed at the lower strain rates on the servo-hydraulic test machine, the load was measured by the load cell of the machine and the machine platen displacement was used to define the nominal strain in the specimen. The end surfaces were lubricated with PTFE spray to reduce frictional restraint.

\subsection{Split Hopkinson pressure bar arrangement}

The split Hopkinson pressure bar (SHPB) technique was brought to maturity by Kolsky [21] as a means of determining the stress versus strain relationship of materials at high strain rates. Since this pioneering work, a number of variations of the experimental set-up have been used to investigate the effect of strain rate on the uniaxial response of various materials [22-24].

A brief description of the experimental set-up is given below, with complete details given by Sathiamoorthy [25]. The arrangement of the bars and specimen are shown in Fig. 3. The bars (striker bar, incident pressure bar, transmitter bar and the momentum trap) consist of $12.7 \mathrm{~mm}$ diameter Maraging 300 steel bars of yield strength approximately $1800 \mathrm{MPa}$. The incident pressure bar, the transmitter pressure bar and the momentum trap are $838 \mathrm{~mm}$ long while the striker bar is $406 \mathrm{~mm}$ in length. The faces of all bars were ground flat and parallel. V-blocks support the incident bar, transmitter bar and the momentum trap but do not restrict the passage of the pressure pulse.

The loading pulse is due to axial impact of the incident pressure bar by the striker bar; the striker bar is accelerated to impact velocity by a high-pressure air gun. After impact between the striker bar and incident pressure bar, a compressive wave propagates from the impacted ends into each bar. When this compressive wave reaches the specimen, the incident bar compresses the specimen. The specimen is subjected to an incident pressure pulse of approximately constant amplitude and of a duration proportional to the length of the striker bar. The amplitude of the incident pulse is directly proportional to the impact velocity, and the impact velocity can be controlled by adjusting the pressure of the air gun.

When the compressive loading pulse in the incident pressure bar reaches the specimen, a portion of the pulse is reflected from the interface, while the remainder is transmitted through to the transmitter bar. As discussed in Section 2, shock wave effects within the metallic foam specimens are negligible for impact velocities of less than $50 \mathrm{~m} \mathrm{~s}^{-1}$. Moreover, experiments reported in Section 4 show that the forces at the distal and proximal ends of the impact are approximately equal. This further substantiates the argument that wave propagation effects within the specimen can be neglected and that the specimen is in force equilibrium.

The force and the relative displacement of the ends of the specimen are measured from the continuous strain-time histories in the incident and transmitted pressure bars. These strain pulses 


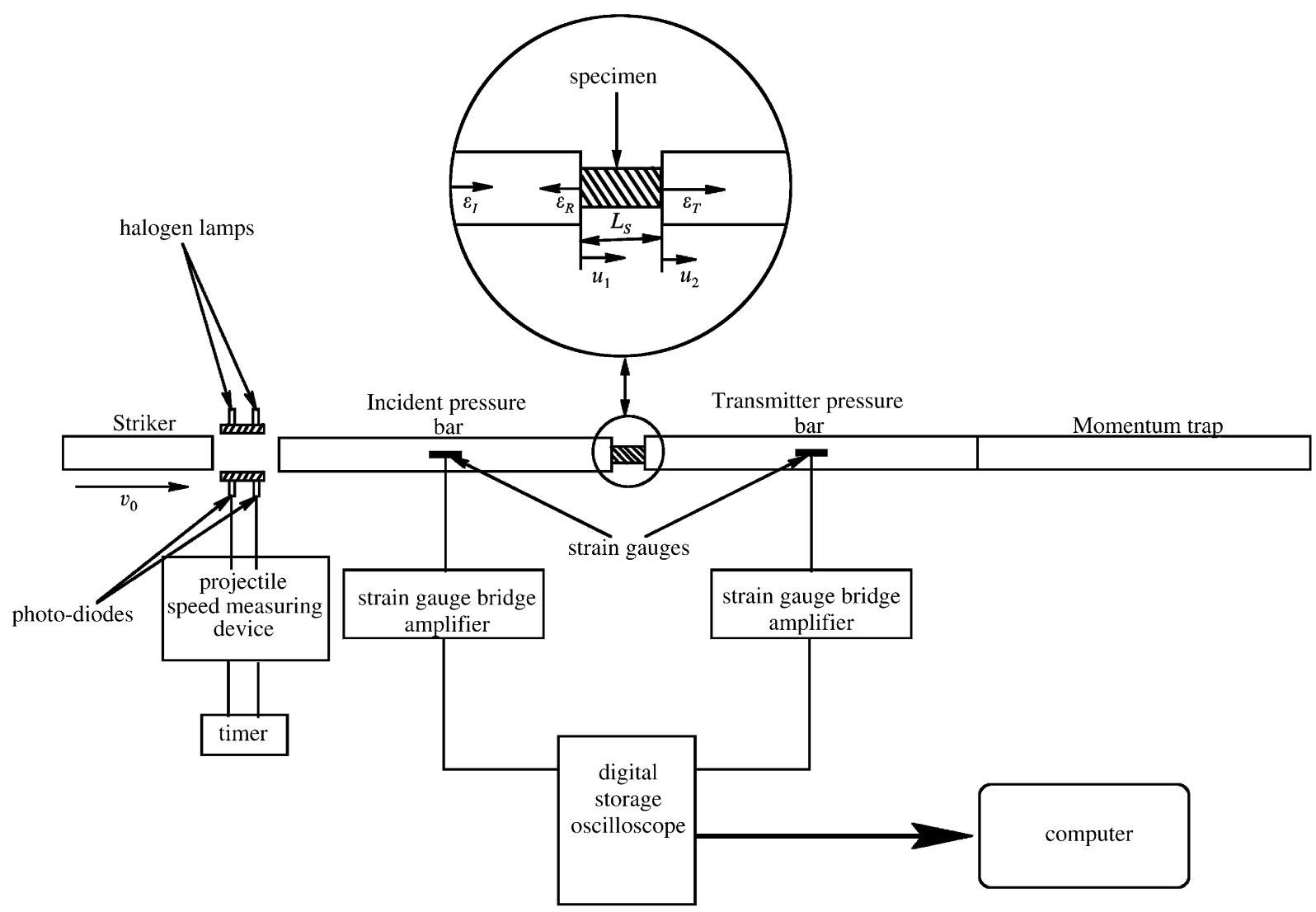

Fig. 3. Schematic of the split Hopkinson pressure bar apparatus.

are recorded by means of resistance strain gauges mounted on the surfaces of the incident and transmitter pressure bars as indicated in Fig. 3. The positioning of the strain gauges on the incident and transmitter pressure bars is important so that continuous records can be obtained of each pulse without interference from reflections from the ends of the bars not in contact with the specimen: the distance between the gauges and the ends of the incident and transmitter pressure bar has to be such that the time taken for the reflected waves to travel from the ends of the bars to the gauges is greater than the duration of the compressive pulse. Thus, the gauges are positioned so that the distance between the gauges and the ends of the respective pressure bars is greater than the length of the striker bar. The length of the incident and transmitter pressure bars is slightly more than twice the length of the striker bar, and the strain gauges were located at the midpoint of the two bars. Typical strain versus time records from the steel pressure bars are shown in Fig. 4. The duration of the incident and reflected pulses in these experiments is $165 \mu \mathrm{s}$. This is the maximum possible duration of the pulses for the length of the incident and transmitter bars used. Hence, no visible separation between the incident and reflected pulse signals is seen in Fig. 4. Experiments with a shorter duration of pulses, through the use of a shorter striker bar of length $200 \mathrm{~mm}$, gave 


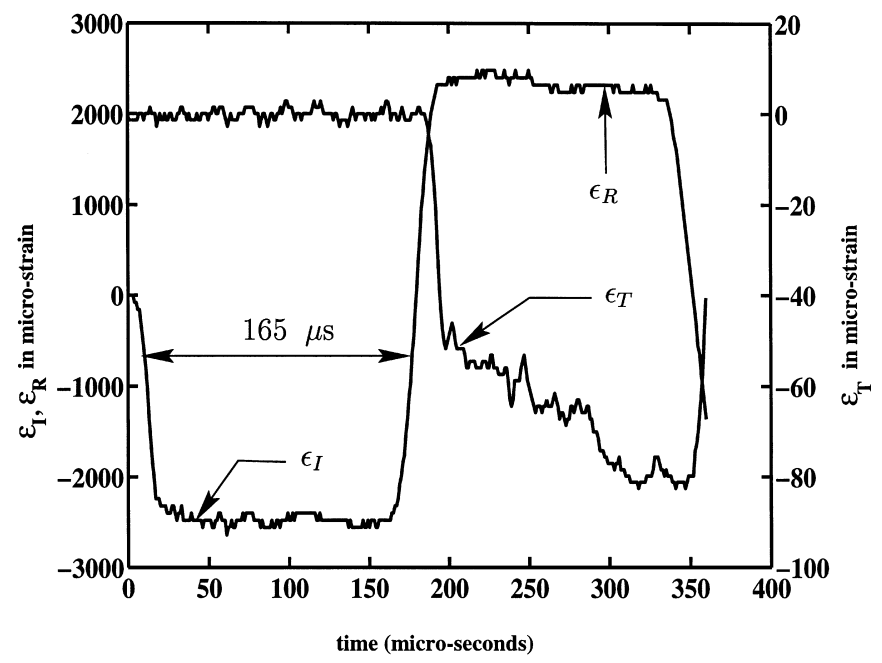

Fig. 4. Strain versus time records from the steel incident and transmitter pressure bars.

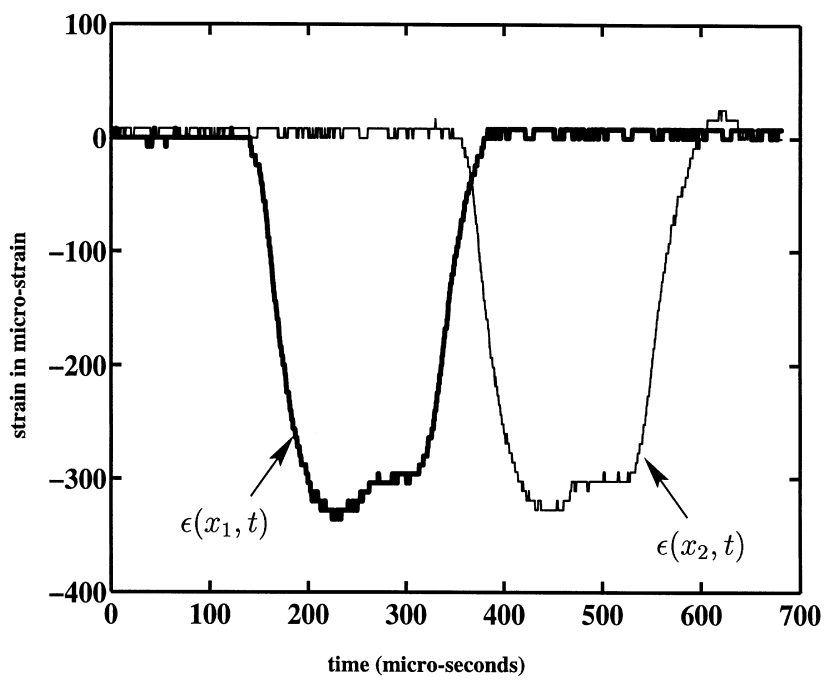

Fig. 5. Strain histories $\varepsilon_{1}$ and $\varepsilon_{2}$ when a PMMA bar of length $838 \mathrm{~mm}$ is impacted longitudinally by a steel bar of length $420 \mathrm{~mm} . \varepsilon_{1}$ and $\varepsilon_{2}$ are measured simultaneously but at a separation of $340 \mathrm{~mm}$ along the PMMA bar.

results consistent with the experiments of longer pulse duration. This confirmed that there is no interference between the incident and reflected pulses recorded on the incident bar.

The basic measurement theory of the standard SHPB is detailed in the appendix. While the standard set-up was adequate to measure the dynamic properties of Alulight, the SHPB needed to be modified to measure the dynamic stress versus strain behaviour of the weaker Duocel. The Duocel foam has a plateau stress of only about $1 \mathrm{MPa}$ and so, the strain $\varepsilon_{\mathrm{T}}$ in the steel transmitter bar was too small to be measured with any degree of confidence. To increase the sensitivity of the 


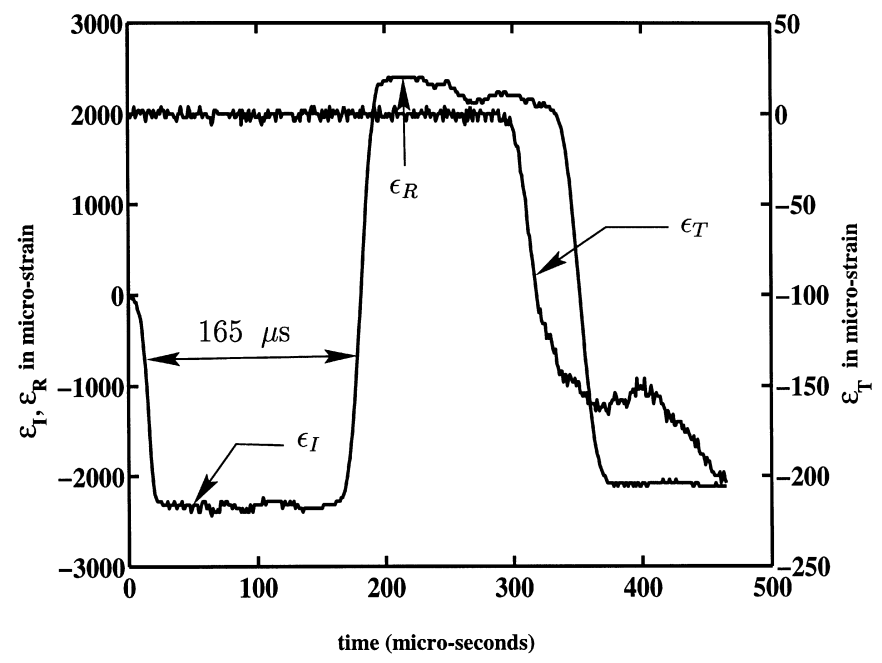

Fig. 6. Strain versus time records from the steel incident and PMMA transmitter pressure bars. The test was performed on a Duocel specimen of relative density 0.070 . The impact speed of the striker was $22 \mathrm{~m} \mathrm{~s}^{-1}$.

apparatus the steel transmitter bar was replaced by a PMMA transmitter bar. The Young's modulus of PMMA is $3.4 \mathrm{GPa}$ compared to $210 \mathrm{GPa}$ for steels, and so the strain level in PMMA is about 60 times that for steels. PMMA bars have been used in previous SHPB studies (e.g. [26,27]); in these investigations the strain signals were large (about $1 \%$ ) and viscoelastic wave theory was found to be necessary. In the present study the maximum strain in the PMMA transmitter bar was approximately $0.05 \%$, and viscoelastic effects were shown to be negligible by the following preliminary test. Two strain gauges were placed $340 \mathrm{~mm}$ apart on a PMMA bar of overall length $838 \mathrm{~mm}$. Fig. 5 shows the strain histories when this bar was impacted by a steel bar of length 420 $\mathrm{mm}$, at a speed of $0.6 \mathrm{~m} \mathrm{~s}^{-1}$. The test was designed such that the strain amplitude $(\approx 350$ micro-strain), maximum strain rate $\left(\approx 7 \mathrm{~s}^{-1}\right)$ and pulse duration $(\approx 165 \mu \mathrm{s})$ in the PMMA bar in the preliminary test are approximately equal to those in the tests on foam specimens (Fig. 6). A comparison of the two signals in the preliminary test shows that the attenuation in the wave amplitude is less than $3 \%$ and that the dispersion is negligible. It is concluded that simple elastic wave theory is adequate for the present study.

\subsubsection{Recording system and calibration}

The recording system is sketched in Fig. 3. The pulses $\varepsilon_{\mathrm{R}}$ and $\varepsilon_{\mathrm{T}}$ in the steel incident and transmitter bars were used to determine the stress-strain state within the Alulight specimen by making use of Eqs. (A.7) and (A.10). Similarly, the pulse $\varepsilon_{\mathrm{R}}$ in the steel incident bar and the pulse $\varepsilon_{\mathrm{T}}$ in the PMMA transmitter bar were used to determine the stress-strain state in the Duocel specimen, via (A.11). Two strain gauges on each bar were connected in a half-bridge circuit to record the axial strain (and cancel any contribution from bending). The outputs from the strain gauge amplifiers were fed into a digital storage oscilloscope for data capture and were then recorded using a personal computer, for subsequent data analysis. 
A dynamic calibration of the strain gauges was performed for the case of incident and transmitter bars made from steel. Simple momentum considerations and wave theory dictate that the maximum strain in the pressure bars $\varepsilon_{\max }$ equals

$$
\varepsilon_{\max }=\frac{v_{0}}{2 c}
$$

where $v_{0}$ is the impact velocity of the striker bar. The impact velocity, $v_{0}$ was measured by timing the passage of the striker between two light beams, and an elastic wave speed $c=5000 \mathrm{~m} \mathrm{~s}^{-1}$ was assumed. The strain gauge calibration was checked dynamically using relation (2). Additionally, the linearity of the system was checked by varying the magnitude of the impact velocity, $v_{0}$.

\subsection{Direct impact tests}

In the split Hopkinson pressure bar, the strain gauge on the transmitter bar is used to measure the normal traction at the interface between the specimen and the downstream transmitter bar. We shall refer to this traction on the specimen as the downstream stress at the distal face. In order to determine whether the specimen is in force equilibrium during the SHPB test, a measurement of the force $F_{1}$ on the proximal face of the specimen is required. Unfortunately, the reflected and incident strain signals in the incident bar are of comparable magnitudes, and so it is not possible to measure $F_{1}$ accurately using the SHPB apparatus. Therefore, independent measurements of the force $F_{1}$ at the impact surface (proximal end) were made using a direct impact test; a similar technique was employed by Reid and Peng [13] and Harrigan et al. [28] for measuring the dynamic crush strengths of woods. In the direct impact test, the specimen is fired by a gas gun onto the flat end of a strain-gauged transmitter bar, and the strain signal is used to measure the stress at the impact face of the specimen. Following Reid and Peng [13] and Harrigan et al. [28] we attached a mass to the back face of the specimen in order to provide additional kinetic energy and to improve alignment of the specimen within the barrel of the gun. This test was used to measure the proximal stress versus average strain response within the foam specimens, in contrast to the SHPB apparatus, which measured the distal stress versus average strain response of the specimens.

Cylindrical specimens of diameter and length $10 \mathrm{~mm}$ were attached to the front of the same striker rod as that used in the split Hopkinson bar experiments, and were fired from the high-pressure air gun. The velocity of the specimen immediately prior to impact was measured by timing the passage of the specimen between two narrow light beams. The specimen impacted the transmitter bar taken from the SHPB apparatus. This method of transient strain measurement is relatively free from load-cell ringing effects which tend to distort the signals. A calibration of the bar allows the strain gauge outputs to be transformed to load pulses. For reasons detailed in the previous section a steel Hopkinson pressure bar was used for the Alulight specimens and a PMMA pressure bar was used for the Duocel foam specimens.

The kinetic energy of the striker at impact velocities exceeding approximately $5 \mathrm{~m} \mathrm{~s}^{-1}$ is much greater than the energy required to plastically deform the aluminium foam specimens up to their densification strain $\varepsilon_{\mathrm{D}}$. Thus, the velocity of the striker can be assumed to be constant during the 
crushing of the foam and the average strain $\varepsilon$ accumulated within the specimen is given by

$$
\varepsilon=\frac{v_{0} t}{L_{\mathrm{s}}} \quad \text { for } \varepsilon<\varepsilon_{\mathrm{D}}
$$

where $v_{0}$ is the impact velocity, $t$ is the elapsed time after impact and $L_{\mathrm{s}}$ is the initial length of the specimen.

\section{Compression experiments on Alulight and Duocel}

Fig. 7 shows a typical nominal stress versus nominal strain curve for quasi-static (strain rate $=10^{-3} \mathrm{~s}^{-1}$ ) compression of Alulight, of relative density 0.17 . The curve has the following four characteristics:

1. an initial linear elastic region;

2. an yield point;

3. a plateau region where the stress increases slowly as the cells deform plastically, and

4. a region of rapidly increasing load as the cell edges progressively touch each other.

The quasi-static deformation of Alulight foam is concentrated within bands which encompass a row of cells across the width of the specimen. These bands deform to about $30 \%$ local strain and then additional deformation occurs in non-adjacent bands. With increasing plastic strain the number of bands of crushed material increases. At overall macroscopic strains greater than about $40 \%$ the whole specimen has crushed and uniform additional straining occurs as discussed by McCullough et al. [17].

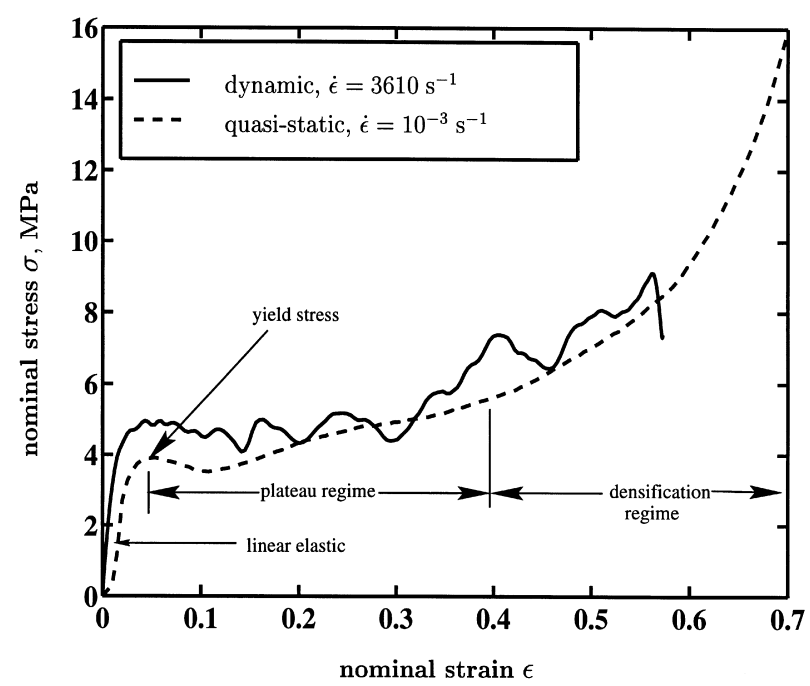

Fig. 7. Comparison between quasi-static and dynamic (SHPB) compression of Alulight, relative density 0.17. 
Table 1

Plateau stress (defined as the stress at $10 \%$ nominal axial strain) values for Alulight of $\rho / \rho_{\mathrm{s}} \approx 0.3$ over a range of strain rates $10^{-3} \mathrm{~s}^{-1} \leqslant \dot{\varepsilon} \leqslant 4000 \mathrm{~s}^{-1}$

\begin{tabular}{lll}
\hline$\rho / \rho_{\mathrm{s}}$ & $\dot{\varepsilon}\left(\mathrm{s}^{-1}\right)$ & $\sigma_{\mathrm{pl}}(\mathrm{MPa})$ \\
\hline 0.30 & $10^{-3}$ & 10 \\
0.30 & $10^{-3}$ & 9.8 \\
0.32 & $10^{-3}$ & 12 \\
0.29 & 1880 & 11 \\
0.30 & 2170 & 10 \\
0.31 & 3920 & 11 \\
0.32 & 2290 & 12 \\
0.32 & 2870 & 12.5 \\
0.32 & 3680 & 11 \\
\hline
\end{tabular}

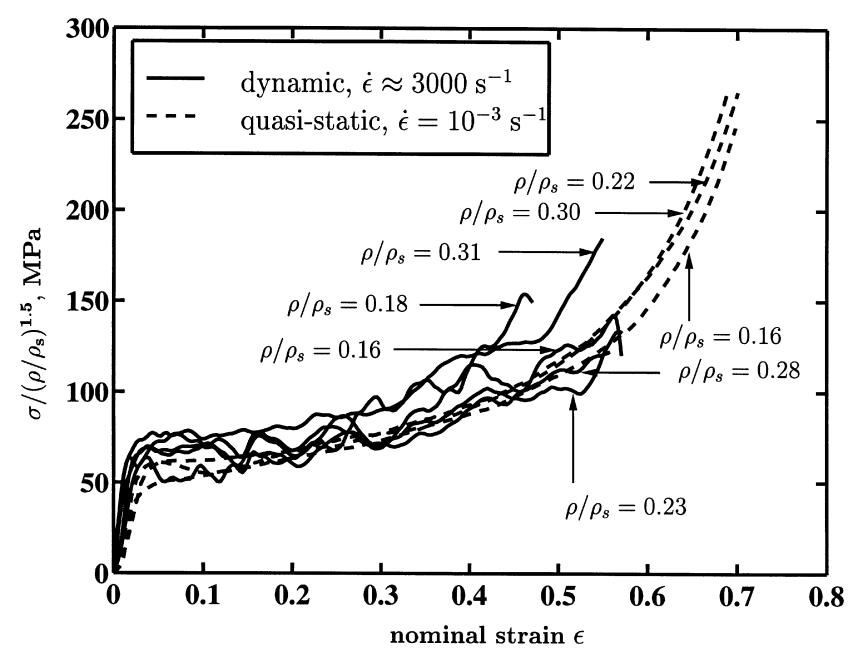

Fig. 8. Comparison between quasi-static and dynamic (SHPB) compression of Alulight for a relative density $\rho / \rho_{\mathrm{s}}$ in the range $0.16-0.31$. Two quasi-static curves $\left(\dot{\varepsilon}=10^{-3} \mathrm{~s}^{-1}\right)$ and five dynamic curves $\left(\dot{\varepsilon} \approx 3000 \mathrm{~s}^{-1}\right)$ are plotted. The stresses have been normalised to remove the effect of relative density.

Fig. 7 includes a nominal stress versus strain curve for Alulight of relative density 0.17 , obtained using the split Hopkinson bar apparatus at a nominal strain rate of $3610 \mathrm{~s}^{-1}$. The shapes of the dynamic and static curves are very similar (i.e. the same four characteristic regions of deformation), with the value of the plateau stress $\sigma_{\mathrm{pl}}$ (stress at $10 \%$ nominal strain) approximately the same in both cases. Plateau stress values for the Alulight foam of relative density $\rho / \rho_{\mathrm{s}} \approx 0.3$ for strain rates ranging from $10^{-3}$ to $4000 \mathrm{~s}^{-1}$ are summarised in Table 1 . It shows that the plateau stress is insensitive to strain rate to within material scatter for tests at a fixed relative density. Fig. 8 shows quasi-static $\left(\dot{\varepsilon}=10^{-3} \mathrm{~s}^{-1}\right)$ and dynamic $\left(\dot{\varepsilon} \approx 3000 \mathrm{~s}^{-1}\right)$ stress versus strain curves for various 


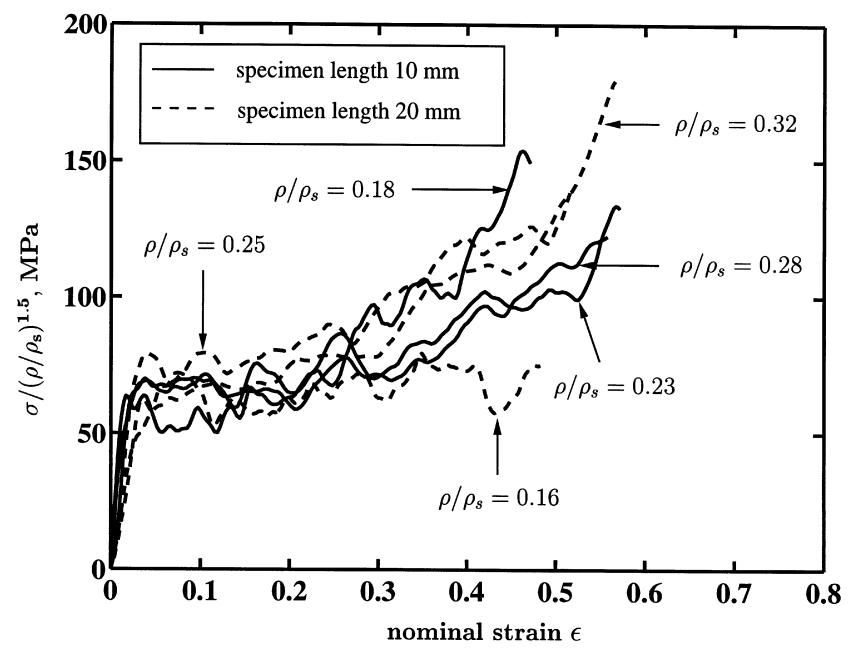

Fig. 9. Comparison between the dynamic $\left(\dot{\varepsilon} \approx 3000 \mathrm{~s}^{-1}\right)$ stress versus strain curves of Alulight specimens 10 and $20 \mathrm{~mm}$ in length. The stresses have been normalised to remove the effect of relative density.

densities of Alulight. Recall that the quasi-static plateau stress $\sigma_{\mathrm{pl}}$ of Alulight scales with the relative density $\rho / \rho_{\mathrm{s}}$ to the power 1.5 [17]. A similar scaling law is appropriate for the open-cell Duocel foam, see [29]. Thus, to reduce the scatter associated with specimens of different relative density, the stresses in Fig. 8 have been normalised by $\left(\rho / \rho_{\mathrm{s}}\right)^{1.5}$. Again, the plateau stress is seen to be insensitive to the strain rate to within material scatter and the error associated with the normalisation. The only significant difference between the dynamic and static stress versus strain curves is that, while the static curves are smooth, oscillations can be seen in the dynamic stress versus strain curves. These oscillations were observed for strain rates above approximately $50 \mathrm{~s}^{-1}$ and were approximately equal in number to the number of crush bands formed. Fig. 9 shows dynamic stress versus strain curves for two lengths $(10$ and $20 \mathrm{~mm})$ of Alulight foam specimens. The shapes of the curves are similar and show no effect of specimen length on the stress versus strain curves of the Alulight foams.

Typical quasi-static nominal stress versus nominal strain curves for Duocel foam of relative density 0.070 are shown in Fig. 10. The shapes of the curves are qualitatively the same as for the Alulight foam. However, the mode of deformation is different for the two foams: for the Duocel foam deformation is uniform with no band formation $[18,30]$, whereas crush bands form within the Alulight.

The high strain rate behaviour of the Duocel foam was measured using the split Hopkinson bar apparatus and the PMMA transmitter bar, at strain rates in the range 1000-3000 s $\mathrm{s}^{-1}$. Tests at strain rates above $3000 \mathrm{~s}^{-1}$ could not be performed as the PMMA transmitter bar consistently fractured. Typical dynamic nominal stress versus strain curves are shown in Fig. 10: the dynamic response agrees with the quasi-static response to within material scatter. A noticeable difference between the dynamic behaviours of Alulight and Duocel is that the dynamic stress versus strain curves of Alulight have oscillations while the corresponding Duocel curves are relatively smooth. 


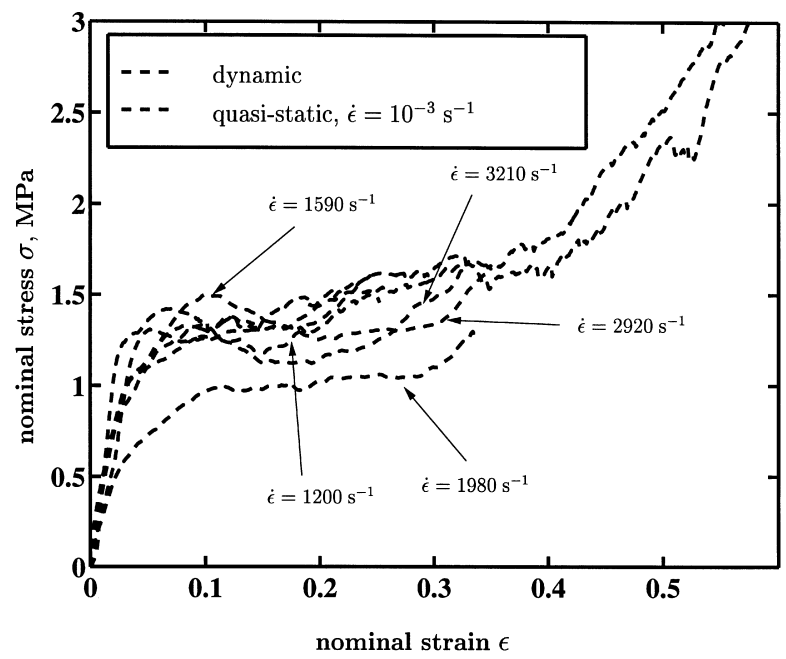

Fig. 10. Comparison between quasi-static and dynamic (SHPB) compression of Duocel (A16101-T6), relative density $\rho / \rho_{\mathrm{s}}=0.070$. Two quasi-static and five dynamic curves $\left(1200 \mathrm{~s}^{-1} \leqslant \dot{\varepsilon} \leqslant 3210 \mathrm{~s}^{-1}\right)$ are shown. There is no consistent trend with increasing strain rate.

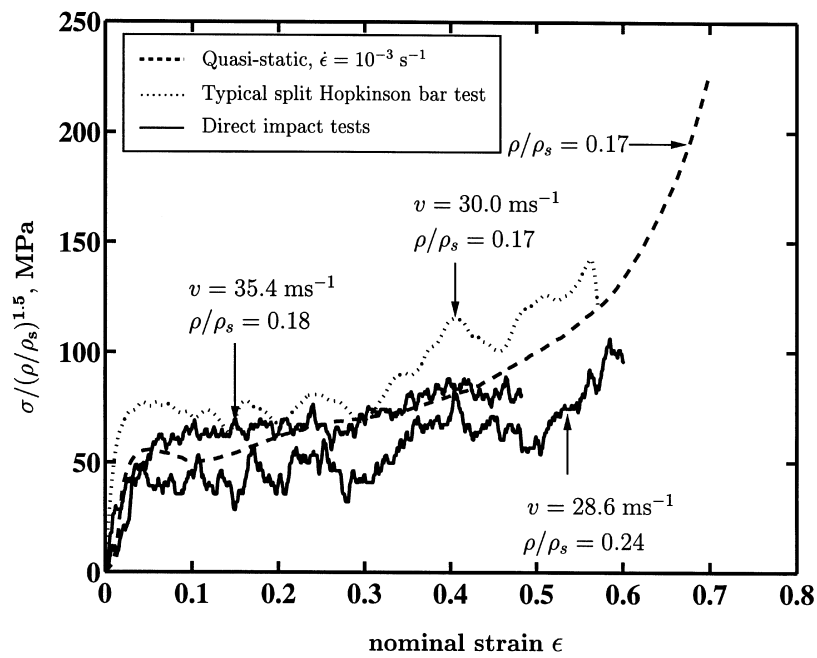

Fig. 11. Comparison between stress versus strain responses of Alulight obtained from quasi-static, split Hopkinson bar and direct impact tests. The stresses have been normalised to remove the effect of relative density. An impact velocity of $30 \mathrm{~m} \mathrm{~s}^{-1}$ corresponds to an average strain rate of $\dot{\varepsilon}=3000 \mathrm{~s}^{-1}$.

A comparison between the stress versus strain responses obtained from quasi-static, split Hopkinson bar and direct impact tests is shown in Figs. 11 and 12 for the Alulight and Duocel foams, respectively. The shapes of the stress versus strain curves obtained from the three types of tests are similar and suggest that force equilibrium prevails within the specimen during the dynamic tests. 


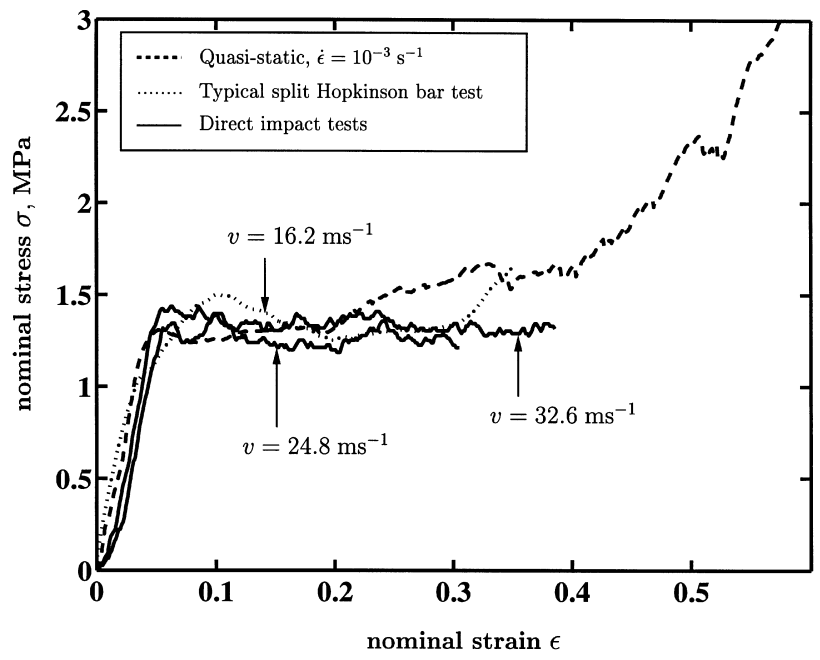

Fig. 12. Comparison between stress versus strain responses of the $7.0 \%$ relative density Duocel obtained from quasi-static, split Hopkinson bar and direct impact tests. An impact velocity of $16 \mathrm{~m} \mathrm{~s}^{-1}$ corresponds to an average strain rate of $\dot{\varepsilon}=1600 \mathrm{~s}^{-1}$.

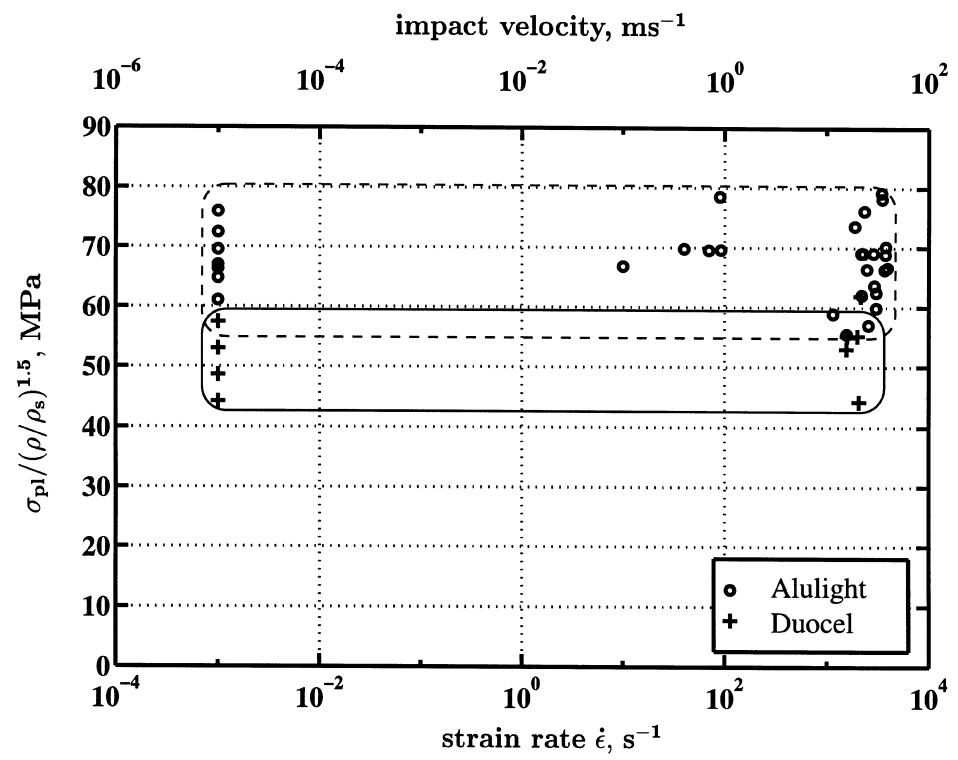

Fig. 13. Variation of plateau stress $\sigma_{\mathrm{pl}}$ with strain rate $\dot{\varepsilon}$ for Alulight and Duocel. Tests at $\dot{\varepsilon}=10^{-3}-100 \mathrm{~s}^{-1}$ were performed using a servo-hydraulic test machine, whereas tests at $\dot{\varepsilon}>10^{3} \mathrm{~s}^{-1}$ were performed using a split Hopkinson pressure bar.

The effect of strain rate on the plateau stress $\sigma_{\mathrm{pl}}$ (stress at $10 \%$ nominal strain) is shown in Fig. 13 for Alulight and Duocel. The plateau stress has been normalised by $\left(\rho / \rho_{\mathrm{s}}\right)^{1.5}$ to eliminate the effect of relative density on the plateau stress of the foams, as already mentioned. We conclude 
that the plateau stresses of both Alulight and Duocel are independent of applied strain rate to within the experimental scatter associated with such materials.

\section{Discussion}

Fig. 14 is a photograph of an Alulight specimen deformed dynamically to $10 \%$ nominal axial strain and sectioned along its diametrical mid-plane. It can be seen that most of the deformation is concentrated in the two zones marked in Fig. 14. Examination of a large number of specimens tested at high strain rates revealed that the crush bands were randomly located. The qualitative deformation pattern is similar to that for specimens tested at quasi-static loading rates, see for example [16]. Further, recall from Fig. 9 that dynamic tests on two different lengths of Alulight foam specimens showed no effect of specimen length on the dynamic stress versus strain curves. We conclude that a macroscopic average strain suffices to describe the overall plastic deformation provided that the length-scale of the specimen is much larger than the crush band width. We

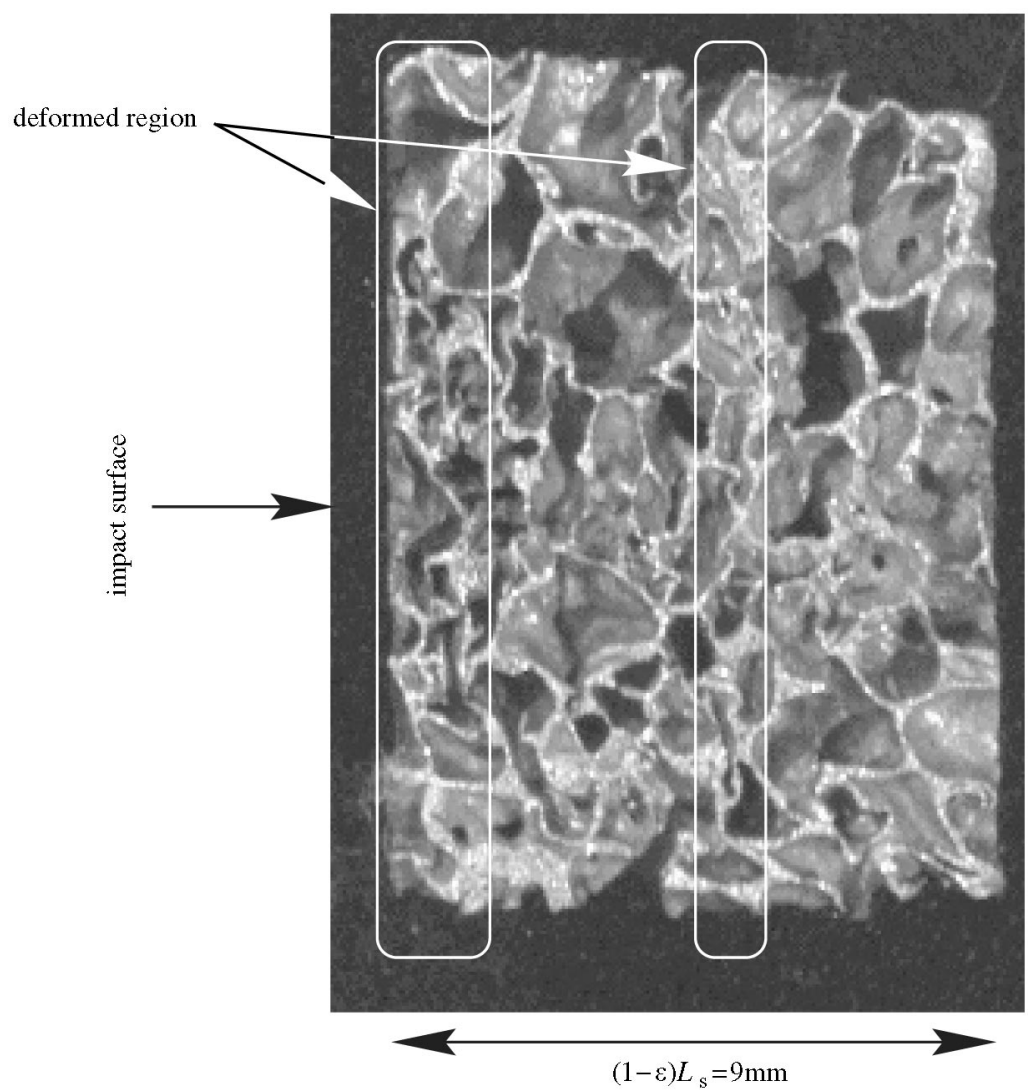

Fig. 14. Photograph of an Alulight specimen deformed to $10 \%$ average strain at a strain rate $\dot{\varepsilon}=3400 \mathrm{~s}^{-1}$ and sectioned along its mid-plane. The specimen is of initial length $L_{\mathrm{s}}=10 \mathrm{~mm}$. 


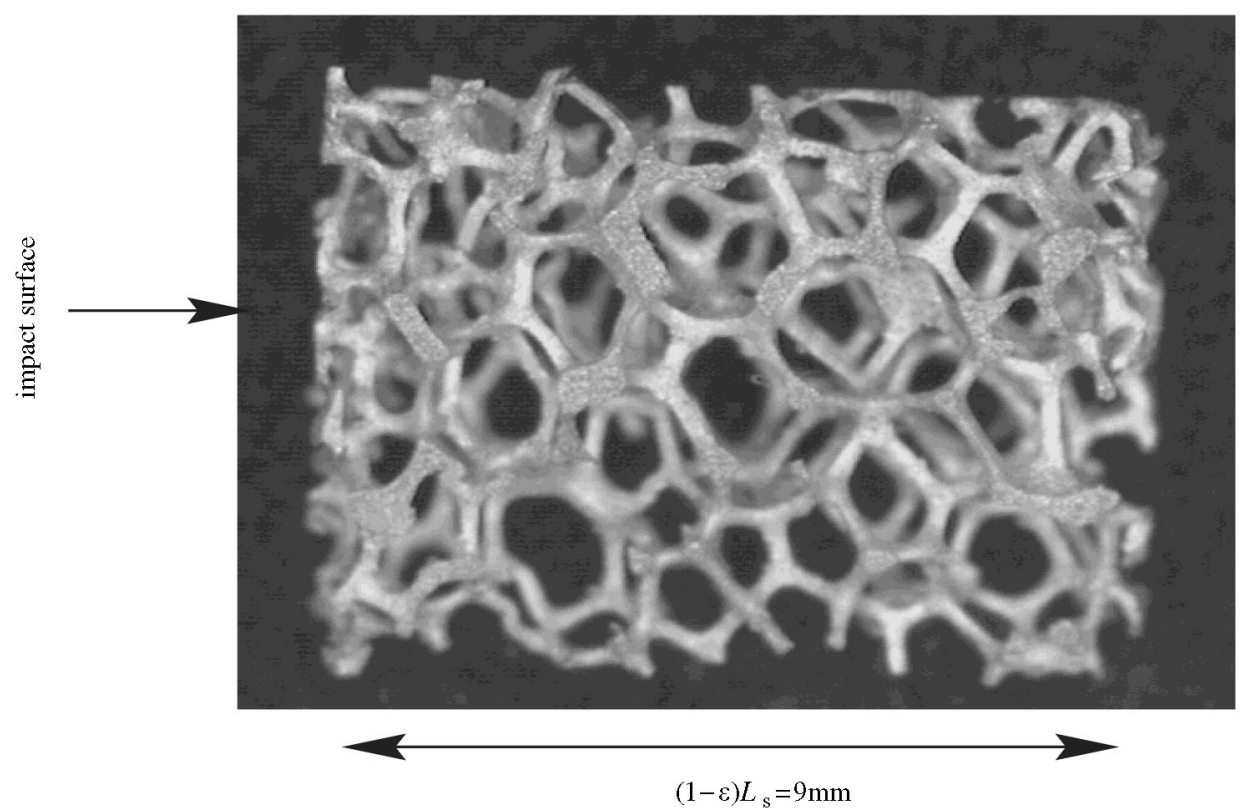

Fig. 15. Photograph of a Duocel specimen deformed to $10 \%$ average strain at a strain rate $\dot{\varepsilon}=1200 \mathrm{~s}^{-1}$ and sectioned along its mid-plane. The specimen is of initial length $L_{\mathrm{s}}=10 \mathrm{~mm}$.

emphasise that the sequence of crushing in highly heterogeneous foams is qualitatively different from the crush band propagation mode observed in uniform structures, such as hexagonal honeycombs and arrays of tubes.

Fig. 15 is a photograph of a Duocel foam specimen deformed dynamically to an average nominal axial strain of $10 \%$, and sectioned along its diametrical mid-plane. The deformation is uniform: the Duocel foam crushed in a spatially uniform manner at both quasi-static rates [30] and in the dynamic split Hopkinson bar tests.

We conclude that, for both foams tested, the mode of collapse is qualitatively the same under quasi-static and dynamic $\left(\dot{\varepsilon}<5000 \mathrm{~s}^{-1}\right)$ loadings. Further, no significant stress enhancements are seen for impact velocities of up to $50 \mathrm{~m} \mathrm{~s}^{-1}$ with the force at the distal end of the specimen equal to that at the proximal end (compare the SHPB and direct impact tests). This is consistent with the arguments presented in Section 2: micro-inertia and shock wave propagation do not significantly affect the properties of metallic foams for the range of impact velocities employed. It remains to consider the effects upon the dynamic strength of (i) strain rate sensitivity of the cell wall material, and (ii) entrapped air within the closed-cell foams.

\subsection{Effect of strain rate sensitivity of the cell wall material}

The plastic deformation of metals is by a number of thermally activated processes, such as dislocation glide. As such, a degree of strain rate sensitivity is expected for aluminium alloy foams. A simplified analysis to quantify this effect is presented below. 


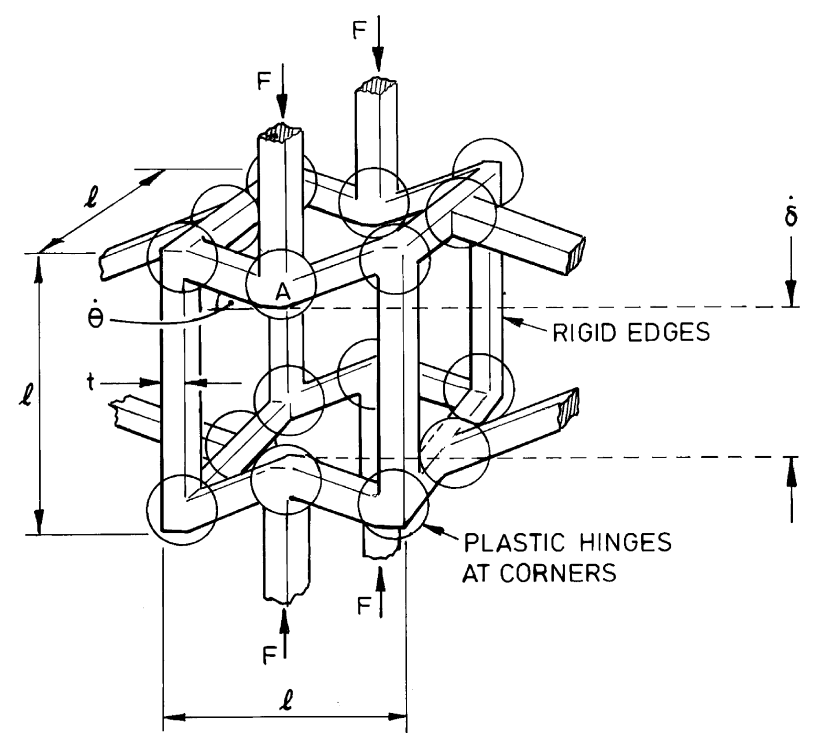

Fig. 16. Kinematics of plastic deformation [29].

The kinematics of plastic deformation in an open-cell foam are shown in Fig. 16, as discussed by Gibson and Ashby [29]. For an applied displacement rate $\dot{\delta}$, a typical plastic hinge "A" undergoes a rotation rate $\dot{\theta}$ given by

$$
\dot{\theta} \approx \frac{\dot{\delta}}{l}
$$

where $l$ is the cell size. The macroscopic strain rate of the foam is

$$
\dot{\varepsilon} \approx \frac{\dot{\delta}}{l}
$$

We follow Calladine and English [14] and make the argument that hinges have an effective length $\lambda$ of about $4 t$, where $t$ is the cell wall thickness. Thus, the rate of change of curvature, is related to $\dot{\theta}$ by

$$
\dot{\kappa}=\frac{\dot{\theta}}{\lambda} .
$$

By the geometry of simple bending, the "extreme fibre" strain rate, $\dot{\varepsilon}^{\prime}$, which is taken as a representative value, is

$$
\dot{\varepsilon}^{\prime}=\frac{1}{2} t \dot{\kappa}
$$


Putting these expressions together, we obtain

$$
\dot{\varepsilon}^{\prime} \approx \frac{\dot{\varepsilon}}{8}
$$

Thus, the strain rate in the outer fibres of the cell walls of the foam is approximately an order of magnitude lower than the macroscopic strain rate.

Lindholm [22] conducted high strain rate compression experiments on aluminium and his results are used here to obtain an estimate for the strain rate sensitivity of the cell wall material. $\mathrm{He}$ found that the dynamic stress-strain relation for aluminium can be expressed as

$$
\sigma=\sigma_{0}(\varepsilon)+\sigma_{1}(\varepsilon) \log \left(\frac{\dot{\varepsilon}}{\dot{\varepsilon}_{0}}\right),
$$

where $\dot{\varepsilon}_{0} \equiv 1 \mathrm{~s}^{-1}, \sigma_{0}(\varepsilon)$ is the strain hardening characteristic at a strain rate of $\dot{\varepsilon}=\dot{\varepsilon}_{0}$ and $\sigma_{1}(\varepsilon)$ describes the enhancement in strain hardening at an elevated strain rate $\dot{\varepsilon}>\dot{\varepsilon}_{0}$.

Tabulated values for $\sigma_{0}(\varepsilon)$ and $\sigma_{1}(\varepsilon)$ are given by Lindholm [22]. Using these data for aluminium, the stress at $25 \%$ nominal strain is about $20 \%$ higher for a strain rate $\dot{\varepsilon}^{\prime}$ of $10^{3} \mathrm{~s}^{-1}$ than for a quasi-static strain rate $\left(\dot{\varepsilon}^{\prime}=10^{-3} \mathrm{~s}^{-1}\right)$. Lindholm et al. [31] have also performed dynamic tests on two 6000-series aluminium alloys, with compositions close to those of the Alulight and Duocel foams. They found that the strength increases by less than $10 \%$ when the strain rate $\dot{\varepsilon}^{\prime}$ is increased from $10^{-4}$ to $10^{3} \mathrm{~s}^{-1}$. Thus, the effect of strain rate on the dynamic strength of the cell wall material in aluminium alloy foams is less than the scatter band in strength of the foams.

\subsection{Effect of compressed air pressure in closed-cell foams}

Dynamic tests on closed-cell Alulight foam are associated with the compression of air trapped in the cells; there is insufficient time for the air to escape through the small cracks and voids in the cell walls in high strain rate compression tests. A first-order estimate of the stress elevation due to this mechanism can be made by assuming that the air is completely trapped. Gibson and Ashby [29] have calculated the contribution of compression of the air to the strength of the closed-cell foam. They assume an ideal gas under isothermal compression, and estimate the strength elevation $\Delta \sigma$ to be

$$
\Delta \sigma=\frac{p_{0} \varepsilon_{\mathrm{B}}(1-2 v)}{1-\varepsilon_{\mathrm{D}}(1-2 v)-\rho / \rho_{\mathrm{s}}},
$$

where $p_{0}$ is the atmospheric air pressure, $\varepsilon_{\mathrm{D}}$ is the densification strain and $v$ is the "plastic Poisson's ratio" of the foam. A similar calculation assuming adiabatic compression gives

$$
\Delta \sigma=p_{0}\left[\left(\frac{1-\rho / \rho_{\mathrm{s}}}{1-\varepsilon_{\mathrm{D}}(1-2 v)-\rho / \rho_{\mathrm{s}}}\right)^{\gamma}-1\right],
$$

where $\gamma$ is the ratio of the specific heat capacities, with $\gamma=1.4$ for air.

We shall use (10) and (11) to estimate the elevation in strength $\Delta \sigma$ due to compression of entrapped air. For an Alulight foam of relative density 0.2, we have $\varepsilon_{\mathrm{D}}=0.4$ [17] and $v=0.2$ [8]. 
The stress elevation due to compression of the trapped air equals $0.04 \mathrm{MPa}$ assuming isothermal compression and equals $0.05 \mathrm{MPa}$ assuming adiabatic compression. These elevations are less than $1.5 \%$ of the static strength, and are thus within the scatter associated with these materials. We conclude that the compression of entrapped air gives a negligible contribution to the strength of Alulight closed-cell foam. Plainly, this conclusion also holds for the case of the open-cell Duocel foam.

\section{Concluding remarks}

The high strain rate compressive behaviours of two aluminium alloy foams, Alulight and Duocel were investigated using a split Hopkinson bar apparatus and direct impact tests. Over the range of nominal strain rates employed $\left(10^{-3}-5000 \mathrm{~s}^{-1}\right)$, no elevation of the dynamic stress versus strain curves is observed compared to the corresponding quasi-static curves. Further, the stresses measured at the proximal and distal ends of a dynamically loaded specimen are approximately equal. The plateau stress and the densification strain are seen to be independent of the applied strain rate, but are sensitive to the relative density of the foam. We emphasise that the tests were performed at sufficiently small impact velocities (less than $50 \mathrm{~m} \mathrm{~s}^{-1}$ ) for shock wave effects to be negligible.

The dynamic stress versus strain curves of the closed-cell Alulight foam show oscillations approximately equal in number to the number of crush bands formed. On the other hand, the dynamic stress versus strain curves of the open-celled Duocel are smooth.

A consideration of the mechanisms governing the dynamic deformation of these foams suggests that there is no change in the fundamental collapse mechanism from the quasi-static to the dynamic cases: deformation occurs in localised bands for the Alulight foam and in a uniform manner for the Duocel foam.

\section{Acknowledgements}

The authors are grateful to DARPA/ONR for their financial support through MURI grant number N00014-1-96-1028 for the Ultralight Metal Structures project at Harvard University. The authors would also like to express their gratitude to Profs. M.F. Ashby and S.R. Reid for helpful discussions and to Dr. F. Simancik of the Department of Powder Metallurgy, Slovak Academy of Sciences for providing the Alulight samples.

\section{Appendix. Theory of measurements [32]}

The stress versus strain response of the specimen is determined from the strain gauge readings on the incident and transmitter bars as follows. From one-dimensional theory of elastic wave propagation, the axial displacement $u(t)$ at time $t$ is related to the axial strain history $\varepsilon(t)$ by

$$
u=c \int_{0}^{t} \varepsilon \mathrm{d} t^{\prime},
$$


where $c$ is the elastic wave speed in the bars (e.g. $c=5000 \mathrm{~m} \mathrm{~s}^{-1}$ for steel). The axial displacement $u_{1}$ of the interface between the incident bar and the specimen (Fig. 3) is due to the incident strain pulse $\varepsilon_{\mathrm{I}}$ travelling in the positive axial direction and the reflected pulse $\varepsilon_{\mathrm{R}}$ travelling in the negative axial direction. Thus,

$$
u_{1}=c \int_{0}^{t}\left(\varepsilon_{\mathrm{I}}-\varepsilon_{\mathrm{R}}\right) \mathrm{d} t^{\prime}
$$

Similarly, the displacement $u_{2}$ of the interface between the transmitter bar and the specimen is obtained from the transmitted strain pulse $\varepsilon_{\mathrm{T}}$ as

$$
u_{2}=c \int_{0}^{t} \varepsilon_{\mathrm{T}} \mathrm{d} t^{\prime}
$$

The nominal compressive strain in the specimen $\varepsilon_{\mathrm{s}}$ is

$$
\varepsilon_{\mathrm{S}}=\frac{u_{1}-u_{2}}{L_{\mathrm{s}}}=\frac{c}{L_{\mathrm{s}}} \int_{0}^{t}\left(\varepsilon_{\mathrm{I}}-\varepsilon_{\mathrm{R}}-\varepsilon_{\mathrm{T}}\right) \mathrm{d} t^{\prime},
$$

where $L_{\mathrm{s}}$ is the initial length of the specimen.

The applied axial loads on each face of the specimen are given by

$$
\begin{aligned}
& F_{1}=E_{\mathrm{b}} A_{\mathrm{b}}\left(\varepsilon_{\mathrm{I}}+\varepsilon_{\mathrm{R}}\right), \\
& F_{2}=E_{\mathrm{b}} A_{\mathrm{b}} \varepsilon_{\mathrm{T}},
\end{aligned}
$$

where $E_{\mathrm{b}}$ and $A_{\mathrm{b}}$ are the Young's modulus and cross-sectional area, respectively, of the pressure bars. As discussed in Section 2, shock wave effects within the metallic foam specimens can be neglected for impact velocities of less than $50 \mathrm{~m} \mathrm{~s}^{-1}$. Thus, $F_{1} \approx F_{2}$, and (A.5a) and (A.5b) reduce to

$$
\varepsilon_{\mathrm{T}}=\varepsilon_{\mathrm{I}}+\varepsilon_{\mathrm{R}} .
$$

Eq. (A.4) then simplifies to

$$
\varepsilon_{\mathrm{s}}=-\frac{2 c}{L_{\mathrm{s}}} \int_{\mathrm{o}}^{t} \varepsilon_{\mathrm{R}} \mathrm{d} t^{\prime}
$$

and the strain rate in the specimen $\dot{\varepsilon}_{\mathrm{s}}$ is given by

$$
\dot{\varepsilon}_{\mathrm{s}}=-\frac{2 c}{L_{\mathrm{s}}} \varepsilon_{\mathrm{R}}
$$

The average compressive stress in the specimen $\sigma_{\mathrm{s}}$ is given by

$$
\sigma_{\mathrm{s}}=\frac{F_{1}+F_{2}}{2 A_{\mathrm{s}}}
$$


where $A_{\mathrm{s}}$ is the cross-sectional area of the specimen. Upon noting that $F_{1} \approx F_{2}$, (A.5b) and (A.9) simplify to

$$
\sigma_{\mathrm{s}}=E_{\mathrm{b}}\left(\frac{A_{\mathrm{b}}}{A_{\mathrm{s}}}\right) \varepsilon_{\mathrm{T}}
$$

For the case of a PMMA transmitter bar Eqs. (A.4) and (A.10) are modified to

$$
\begin{aligned}
\varepsilon_{\mathrm{s}} & =\int_{0}^{t}\left[\frac{c}{L_{\mathrm{s}}}\left(\varepsilon_{\mathrm{I}}-\varepsilon_{\mathrm{R}}\right)-\frac{c_{p}}{L_{\mathrm{s}}} \varepsilon_{\mathrm{T}}\right] \mathrm{d} t^{\prime}, \\
\sigma_{\mathrm{s}} & =E_{p}\left(\frac{A_{\mathrm{b}}}{A_{\mathrm{s}}}\right) \varepsilon_{\mathrm{T}},
\end{aligned}
$$

where $c_{p}=1700 \mathrm{~m} \mathrm{~s}^{-1}$ is the elastic wave speed in PMMA and $E_{p}=3.4 \mathrm{GPa}$ is the Young's modulus of PMMA.

\section{References}

[1] Stronge WJ, Shim VP-W. Micro-dynamics of crushing in cellular solids. J Engng Mater Technol ASME 1988;110:185.

[2] Baker WE, Togami TC, Weyder JC. Static and dynamic properties of high-density metal honeycombs. Int J Impact Engng 1998;21(3):149.

[3] Wu E, Jiang W-S. Axial crush of metallic honeycombs. Int J Impact Engng 1997;19(5-6):439.

[4] Harrigan JJ, Peng C, Reid SR. Inertia effects in impact energy absorbing materials and structures. In: Langseth M, Krauthammer T, editors. Proceedings of Transient Loading and Response of Structures, International Symposium honouring Mr Arnfinn Jenssen. Norwegian Defence Construction Service and Department of Structural Engineering, Norwegian University of Science and Technology, Trondheim, TAPIR, May 1998. p. 447. ISBN: 82-7482-0444. See also Int J Impact Engng 1999;22(9-10):965.

[5] Zhao H, Gary G. Crushing behaviour of aluminium honeycombs under impact loading. Int J Impact Engng 1998;21(10):827.

[6] Kenny LD. Mechanical properties of particle stabilised aluminium foam. Mater Sci Forum 1996;217-222:1883.

[7] Lankford J, Dannemann KA. Strain rate effects in porous materials. Proceedings of the Symposium of the Materials Research Society, vol. 521. Materials Research Society, 1998.

[8] Ashby MF, Evans AG, Hutchinson JW, Fleck NA. Metal foams: a design guide. Technical Report CUED/CMICROMECH/TR. 3, Engineering Department, Cambridge University, 1998.

[9] Klintworth JW. Dynamic crushing of cellular solids. PhD Thesis, Department of Engineering, University of Cambridge, 1989.

[10] Reid SR, Reddy TY, Peng C. Dynamic compression of cellular structures and materials. In: Jones N, Wierzbicki T, editors. Structural crash-worthiness and failure. Amsterdam: Elsevier, 1993, p. 295.

[11] Su XY, Yu TX, Reid SR. Inertia-sensitive impact energy-absorbing structures. Part I: Effects of inertia and elasticity. Int J Impact Engng 1995;16(4):651.

[12] Su XY, Yu TX, Reid SR. Inertia-sensitive impact energy-absorbing structures. Part II: Effect of strain rate. Int J Impact Engng 1995;16(4):673.

[13] Reid SR, Peng C. Dynamic uniaxial crushing of wood. Int J Impact Engng 1997;19:531.

[14] Calladine CR, English RW. Strain-rate and inertia effects in the collapse of two types of energy absorbing structures. Int J Mech Sci 1984;26(11/12):689.

[15] Tam LL, Calladine CR. Inertia and strain-rate effects in a simple plate-structure under impact loading. Int J Impact Engng 1991;11(3):349. 
[16] Sugimara Y, Meyer J, He MY, Bart-Smith H, Grenestedt J, Evans AG. On the mechanical performance of closed cell Al alloy foams. Acta Metall Mater 1997;45(12):5245.

[17] McCullough KYG, Fleck NA, Ashby MF. Uniaxial stress-strain behaviour of aluminium alloy foams. Acta Metall Mater 1999;47(8):2323.

[18] Harte A-M, Fleck NA, Ashby MF. Fatigue failure of an open cell and a closed cell aluminium alloy foam. Acta Metall Mater 1999;47(8):2511.

[19] Chen C, Lu TJ, Fleck NA. Effect of imperfections on the yielding of two-dimensional foams. J Mech Phys Solids 1999;47(11):2235.

[20] Deshpande VS, Fleck NA. Isotropic constitutive models for metallic foams. J Mech Phys Solids 2000, to appear.

[21] Kolsky H. An investigation of the mechanical properties of materials at very high rates of loading. Proc Phys Soc of London B 1949;62:676.

[22] Lindholm US. Some experiments with the split-Hopkinson pressure bar. J Mech Phys Solids 1964;12:317.

[23] Hauser FE. Techniques for measuring stress-strain relations at high strain rates. Exp Mech 1966; 395.

[24] Nemat-Nasser S, Isaacs JB, Starret JE. Hopkinson bar techniques for dynamic recovery experiments. Proc Royal Soc London A 1991;435:371.

[25] Sathiamoorthy S. Compressive failure of composites. PhD Thesis, Department of Engineering, University of Cambridge, 1997.

[26] Zhao H, Gary G, Klepaczko JR. On the use of a viscoelastic split Hopkinson bar technique. Int J Impact Engng 1997;19(4):319.

[27] Lili Wang, Labibes K, Azari Z, Pluvinage G. Generalization of split Hopkinson bar technique to use viscoelastic bars. Int J Impact Engng 1998;15(5):669.

[28] Harrigan JJ, Reid SR, Reddy TY. Inertial effects on the crushing of wood loaded along the grain. 11th International Conference on Experimental Mechanics, Oxford, August 1998.

[29] Gibson LJ, Ashby MF. Cellular solids: structure and properties, 2nd ed. Cambridge University Press, Cambridge, 1997.

[30] Bart-Smith H, Bastawros AF, Mumm DR, Evans AG, Sypeck DJ, Wadley HNG. Compressive deformation and yielding mechanisms in cellular $\mathrm{Al}$ alloys determined using X-ray tomography and surface strain mapping. Acta Metall Mater 1998;46(10):3583.

[31] Lindholm US, Bessey RL, Smith GV. Effect of strain rate on yield strength, tensile strength and elongation of three aluminium alloys. J Mater JMLSA 1971;6(1):119.

[32] Kolsky H. Stress waves in solids. Oxford: Clarendon Press, 1953. 